advanced the idea that our modern way of living, the patent roller-made flour, which is deprived of all the coarser part of the flour, and must be of all or nearly all of the carbohydrates, which go largely into the nutritious element of the same. The low price of it puts it within reach of the poorest families, and they, too, indulge in what is called the best grade of flour, when, at the same time, it is the life nutrition, and when you intrude upon native with improved or adulterated foods J many times see that some of the organs and fluids of the body must suffer.

James A. Hopkins, M.D.

\section{Medical Legislation.}

Iow A City, Iowa, Aug. 15, 1897.

To the Editor:-At the meeting of the Iowa State Medical Society, at Des Moines in 1896, discussion was had concerning a project to unite the practitioners of the State into an association to "influence legislation." Nothing was done by the society but subsequently an association was organized and an effort made to secure a union for political purposes of all practicing medicine, including sectarians with various labels. Many declined to unite with the organization; some because they believed the discordant elements would prevent any useful work, and others because they believed that the attempt to organize a political club out of a profession would lead rather to adverse legislation than to any legislative reform of advantage. A circular is the first fruit that has emanated from the association; and it appears to the writer that the introduction of the profession to practical politics of this kind, is undesira ble. The physician has the same rights and duties as other citizens, and experience has shown that the study of medicine does not lessen the capacity of a man to serve the people in legislation or administration. It would probably be better for the country if, as individuals, the members of the medical pro. fession took the practical and active interest in politics that has been so noticeable among their confrères of France. The reproach, that such an association has been used to advance personal interests, can not help lessening its value as a protector of general interests. The association however is not an offshoot or a part of the State Medical Society of Iowa.

"HALLER."

\section{A Suggestion for the Next Meeting.}

Boston, Aug. 18, 1897.

To the Editor:-Permit me to make a suggestion. If it be carried out I think it will add to the interest of our annual meetings. Some of us in the Associstion are engaged upon original work. This work can be presented to our brother members in two ways: by reading a paper about it, and (when it concerns something concrete) presenting the thing itself. The combination method at present employed could be improved on without infringing on the practical work of the Section. Instead of the momentary presentation of instruments, etc., in conjunction with the reading of a paper, would it not be well to have such devices and objects placed where the members could examine them at their leisure? Such an exhibit could be conveniently made in the rear of the hall where the Section meets, or in a reserved space in the usual exhibition hall. It would add nothing to the expense of the meeting, as a few tables is all that would be necessary for the purpose. Members of the Section having instruments, devices, X-ray pictures or other objects of practical interest could thus place them where their fellows could have access to them. If members had the opportunity to get a working knowledge of the new devices that are constantly being applied in the art of surgery, the practical utility of the Section would be increased. In time, perhaps, a surgeon who wished to keep abreast of his art could not afford to miss a meeting of the Association, not alone for what he could hear, but for what he could see. Trust- ing this suggestion will meet with consideration by interested members, I remain, respectfully,

Enward A. Tracy, M.D.

\section{Infectious Disinfectors.}

Groveland, Mass. Aug. 21, 1897.

To the Editor:-The following case was recently reported in the Journal of Hygiene, France: "A child suffering from a light attack of scarlatina is confined to his room for forty days, the room is disinfected by the board of health. Two days later the child presents undoubted symptoms of diphtheria-a patch on one tonsil. The physician in attendance does not doubt that the disinfectors brought this disease, as the child had seen no one but them and the physician who had himself not been exposed."

Such a theory seems hardly tenable. 1 have had cases in my own practice, of mixed infection, and others where diphtheria has followed scarlet fever, the patient ill at first with all the symptoms of scarlet fever and then with those of diphtheria. In none of these cases were cultures made demonstrating the presence of Klebs-Löffler bacilli. More recently I have had under my care a case where the symptoms were unmistakably those of scarlet fever supplemented by symptoms of true diphtheria. In this case cultures failed to show KlebsLöffler bacilli, but supplied abundant evidence of streptococci. That there is a remarkable relationship between diphtheria and scarlet fever there can be no longer any doubt. Those who believe in this theory of unity of disease are finding considera. ble evidence to support their views.

$$
\text { W. Thornton Parker, M.D. }
$$

\section{How the Defunct Osteopathy Bill was Passed by the Illinois Legislature.}

ONeIDA, Ill., Aug. 20, 1897.

To the Editor:-I send you a Journal of Osteopathy. I know something of how they managed the late House at Springfield, which may be of interest, as I am well acquainted with our representative, Murdock. While the bill was being agitated I went to him and asked for his influence against it. He informed me that he was in favor of it, that one of the operators in the cult was at the capital demonstrating the treatment and one of the members who had sometime previously been laid up with an attack of rheumatism for six weeks, was taken suddenly one evening with a similar attack, and the osteopathic gentleman asked to be allowed to treat him just once and was granted the request. $\mathrm{He}$ at once proceeded to carry out the treatment in view of several of the other members. To use Mr. Murdock's expression, "he doubled his legs up and then pulled them out with a snap; thumped and pulled and doubled and rubbed and yanked. The patient the while yelled like a bull." After about half an hour of that he let his victim alone and by the next morning the man was as well as usual. Another patient was also exhibited. A man with dislocated wrist which the "doctors had failed to set or help," and he proceeded to at once replace it and let the man go without splint or bandage. To sum up, the man simply "pulled the leg" of the whole Illinois Legislature. Was it any wonder that the bill passed speedily on for the Governor's signature: But he showed himself a man with decision enough to refuse to sign it, thereby gaining the friendship of every reputable physician in the State and the ill will of a few cranks.

$$
\text { Yours for good, T. W. DAvidson, M.D. }
$$

\section{No Itinerant Quacks in Kentucky.}

Executive Office State Board of Health of Kentuckx, Bowling Green, A ug. 7, 1897.

To the Editor:-After careful examination of the authorities Judge Thompson of Louisville has just handed down his opin- 